\title{
Pearls
}

\section{Pearls: How I Create the Tibial Socket for PCL Reconstruction}

\author{
Bruce A. Levy MD
}

ome of the most difficult aspects of PCL reconstruction are getting to the posterior aspect of the tibia, finding the anatomic insertion site of the PCL, and drilling the tibial socket or tunnel. The popliteal neurovascular structures are in close proximity. Because of this,

Note from the Editor-in-Chief: We are pleased to present the next installment of "Pearls", a new column in Clinical

Orthopaedics and Related Research ${ }^{\circledR}$. In this column, distinguished surgeons, scientists, or scholars share surgical or professional tips they use to help surmount important or interesting problems. We welcome reader feedback on all of our columns and articles; please send your comments to

eic@clinorthop.org.

One of the authors certifies that he (BAL) has received or may receive payments or benefits, during the study period, an amount of less than USD 10,000 from Arthrex Inc, Naples, FL, USA.

All ICMJE Conflict of Interest Forms for authors and Clinical Orthopaedics and

Related Research ${ }^{\mathbb{B}}$ editors and board members are on file with the publication and can be viewed on request.

Clinical Orthopaedics and Related

Research ${ }^{\circledR}$ neither advocates nor endorses the use of any treatment, drug, or device. Readers are encouraged to always seek additional information, including FDA approval status, of any drug or device before clinical use. The opinions expressed are those of the writers, and do not reflect the opinion or policy of $C O R R^{\circledR}$ or The Association of Bone and Joint Surgeons ${ }^{\circledR}$.

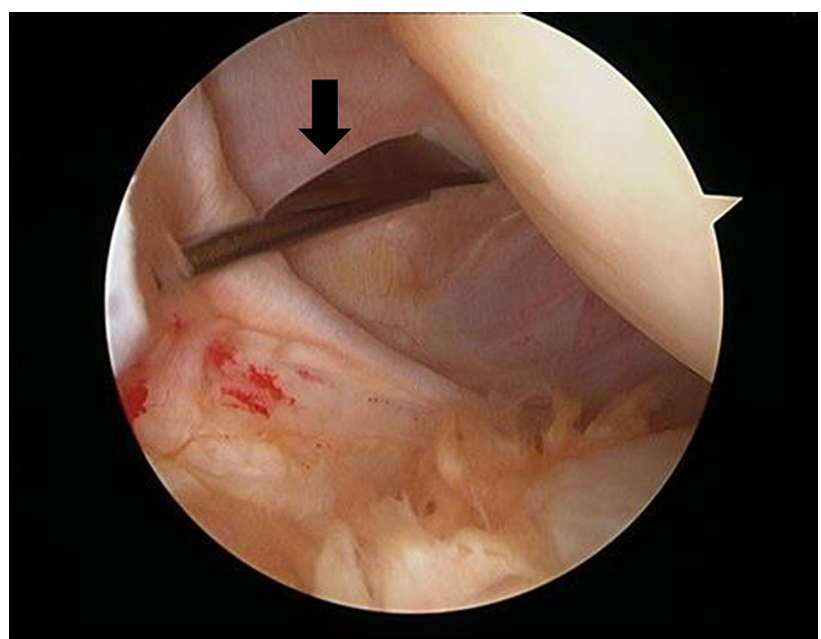

Fig. 1 View from the anterolateral portal establishing the posteromedial portal with the "needle and knife" technique (black arrow). (Reprinted from Operative Techniques in Sports Medicine, King AH, Prince MR, Reardon PJ, Levy BA, Stuart MJ, All-Inside Posterior Cruciate Ligament Reconstruction, Article in Press, Copyright (2015), with permission from Elsevier. http://www.sciencedirect.com/science/journal/10601872).

exposure is critical to ensure safety as well as proper graft placement $[1,5]$.

\section{Arthroscopy Portals}

I typically create two anteromedial and two anterolateral portals when performing combined ACL/PCL

\section{B. A. Levy MD ( $₫)$}

Department of Orthopedic Surgery and Sports Medicine, Mayo Clinic, 200 First Street SW, Rochester, MN 55905, USA e-mail: levy.bruce@mayo.edu reconstructions. Having four portals provides the flexibility needed to ensure proper socket placements on both the femoral and tibial sides.

\section{Tibial Socket Preparation}

Once the ACL and PCL footprints are removed from the femoral side, I carefully resect the anterolateral and posteromedial PCL remnants with a $30^{\circ}$ scope all the way to the level of the posterior horns of the medial and lateral menisci. Using a $30^{\circ}$ scope 


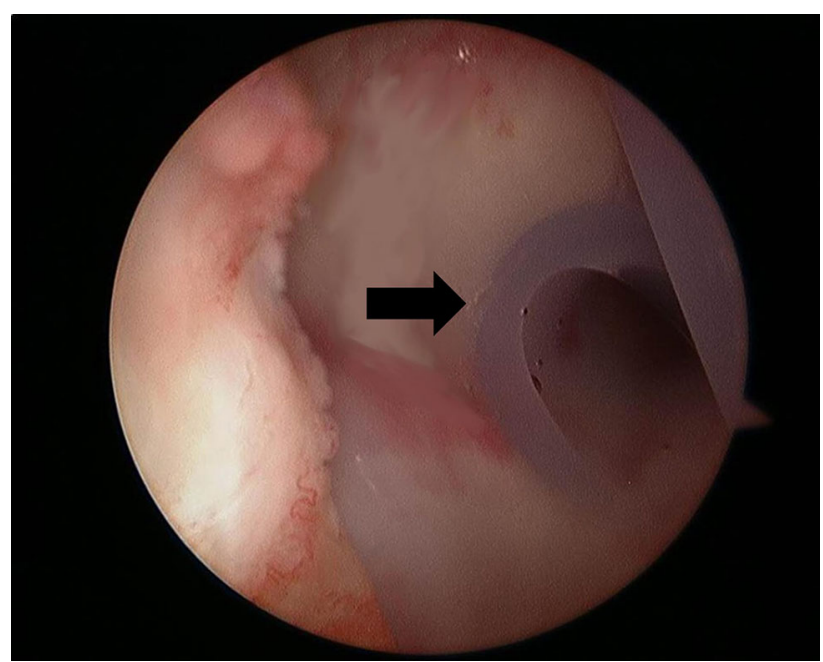

Fig. 2 View from the anterolateral portal showing the insertion of a flexible cannula in the posteromedial portal (black arrow). (Reprinted from Operative Techniques in Sports Medicine, King AH, Prince MR, Reardon PJ, Levy BA, Stuart MJ, All-Inside Posterior Cruciate Ligament Reconstruction, Article in Press, Copyright (2015), with permission from Elsevier. http:// www.sciencedirect.com/science/journal/10601872). provides me with a more "normal" view of the intercondylar notch for cleaning off the femoral and proximal portion of the tibial PCL footprint. It is essential to have excellent visualization of both the posterior horns of the medial and lateral menisci to avoid damaging them. I then establish a posteromedial portal [4]. I place the $30^{\circ}$ scope in the anterolateral portal, dim the OR lights (allowing for illumination of the scope), and place an 18 -gauge spinal needle from the posteromedial aspect of the knee toward the PCL remnant. I observe the needle under direct visualization to ensure that it is not too close to the femoral condyle. If the posteromedial portal is created too close to the femoral 


\section{Pearls}

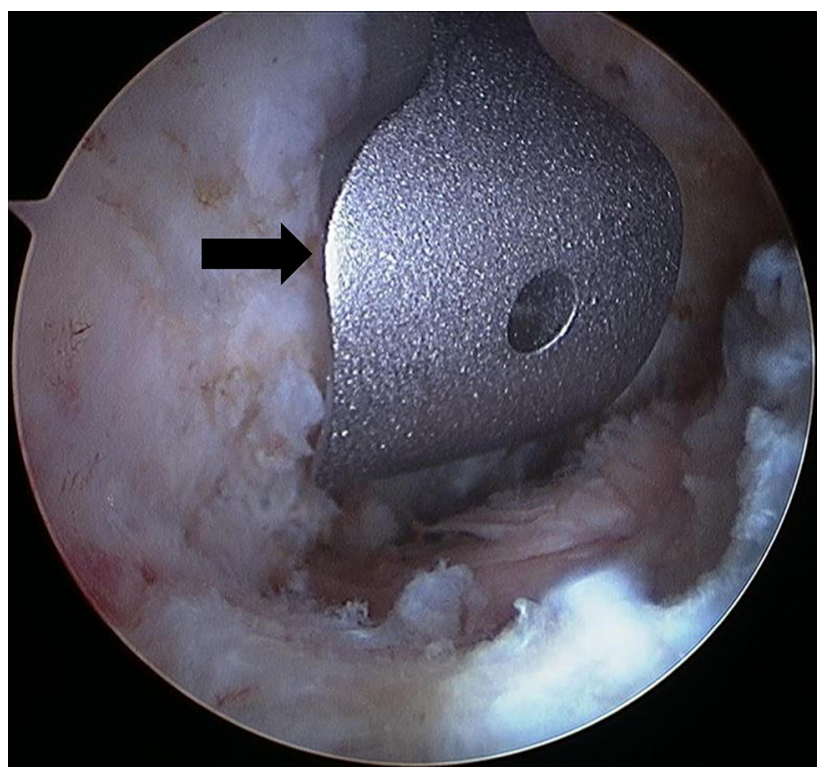

Fig. 3 View from the posteromedial portal showing the position of the PCL tibial guide hugging the base of the PCL facet (black arrow). (Reprinted from Operative Techniques in Sports Medicine, King AH, Prince MR, Reardon PJ, Levy BA, Stuart MJ, All-Inside Posterior Cruciate Ligament Reconstruction, Article in Press, Copyright (2015), with permission from Elsevier. http://www.sciencedirect.com/science/journal/10601872). condyle, it does not give enough freedom to move the shaver or radiofrequency device to clean off the tibial footprint properly. With the needle in the skin, I use a No. 11 blade is used to make a small $5 \mathrm{~mm}$ or $6 \mathrm{~mm}$ longitudinal incision, and place the blade directly above the needle until it enters the joint (Fig. 1). This allows direct visualization of both the needle and the knife, and ensures safety and avoidance of damage to the neurovascular structures. I remove the knife, leaving the needle in place, and then insert a cannula over a switching stick. Soft cannulas are preferred as they give more intraoperative flexibility (Fig. 2). I then use a $70^{\circ}$ scope, as it offers improved visualization all the way to the base of the PCL footprint. I create a soft-tissue plane between the posterior midline septum and the 


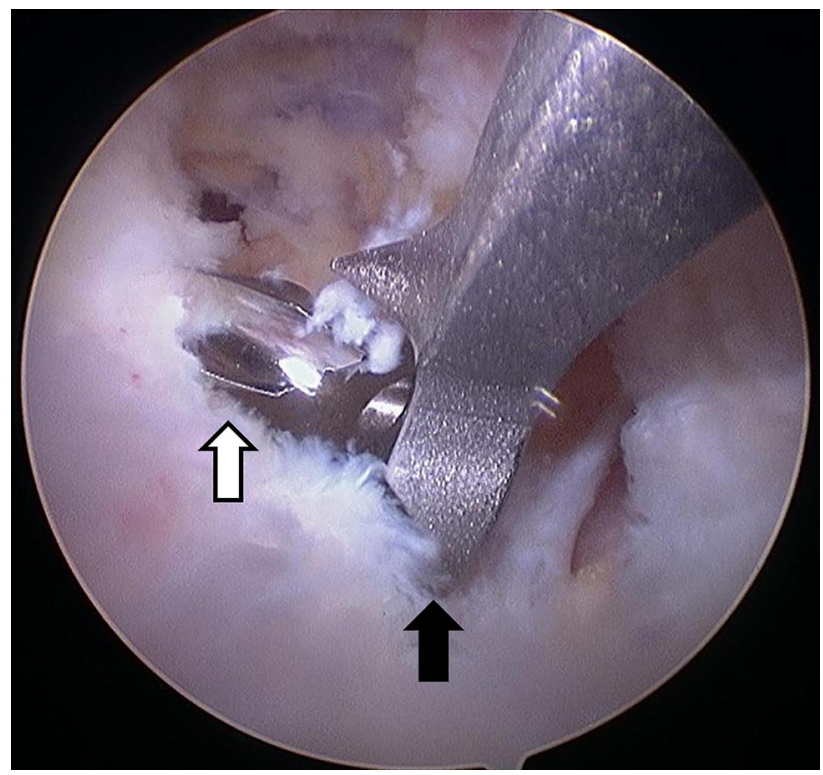

Fig. 4 View from the posteromedial portal of the $2.4 \mathrm{~mm}$ guidepin (white arrow) at the base of the PCL facet as it hits the PCL guide (black arrow) which acts as a neurovascular protector. (Reprinted from Operative Techniques in Sports Medicine, King AH, Prince MR, Reardon PJ, Levy BA, Stuart MJ, All-Inside Posterior Cruciate Ligament Reconstruction, Article in Press, Copyright (2015), with permission from Elsevier. http://www.sciencedirect.com/science/journal/10601872). posterior horn of the medial meniscus. This not only gives me more access to the back of the tibia, but also is a safety measure, as it moves the neurovascular bundle further away from the surgical field [2]. I use the shaver to remove as much of the PCL as possible, and then use a radiofrequency device to get right down on the tibial footprint until it drops off and the popliteus muscle and the mammillary bodies, which lie on either side of the tibial PCL, attachment are visualized. Once I identify the tibial footprint, I position the anatomic contoured PCL guide through the low anteromedial portal and hook the base of the PCL facet, capturing the entire tibial footprint (Fig. 3). Once the guide is locked in place, I drill a $2.4 \mathrm{~mm}$ guide pin with the $70^{\circ}$ scope in the posteromedial portal. This allows direct 


\section{Pearls}

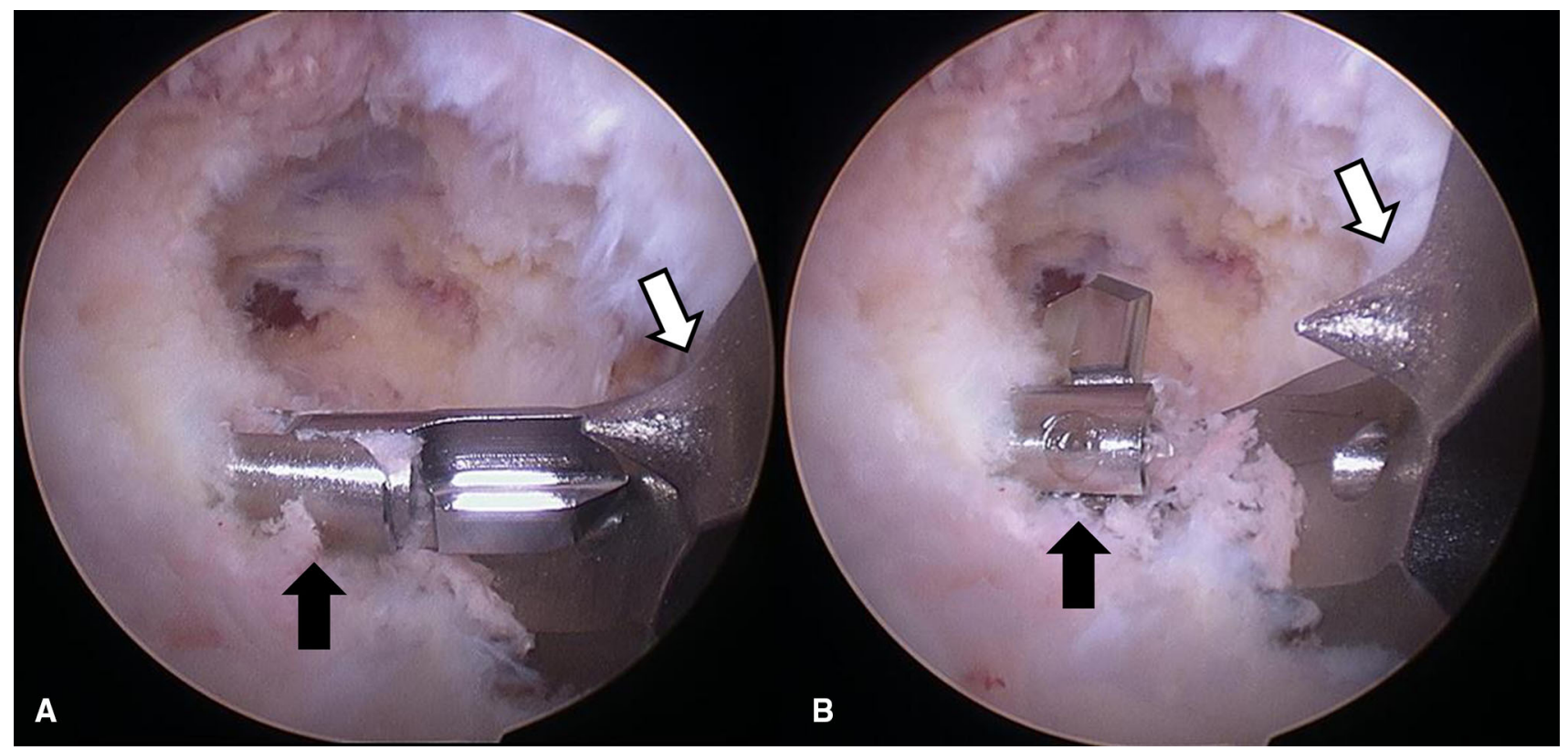

Fig. 5A-B (A) View from the posteromedial portal showing the $11 \mathrm{~mm}$ retro cutting device (black arrow) at the base of the $P C L$ facet as it hits the PCL guide (white arrow), which acts as a neurovascular protector. (B) View from the posteromedial portal showing the $11 \mathrm{~mm}$ retro cutting device in a flipped position (black arrow) at the base of the PCL facet. Note the tibial guide (white arrow) is still in place as a neurovascular protector. (Reprinted from Operative Techniques in Sports Medicine, King AH, Prince MR, Reardon PJ, Levy BA, Stuart MJ, AllInside Posterior Cruciate Ligament Reconstruction, Article in Press, Copyright (2015), with permission from Elsevier. http:// www.sciencedirect.com/science/journal/10601872). 


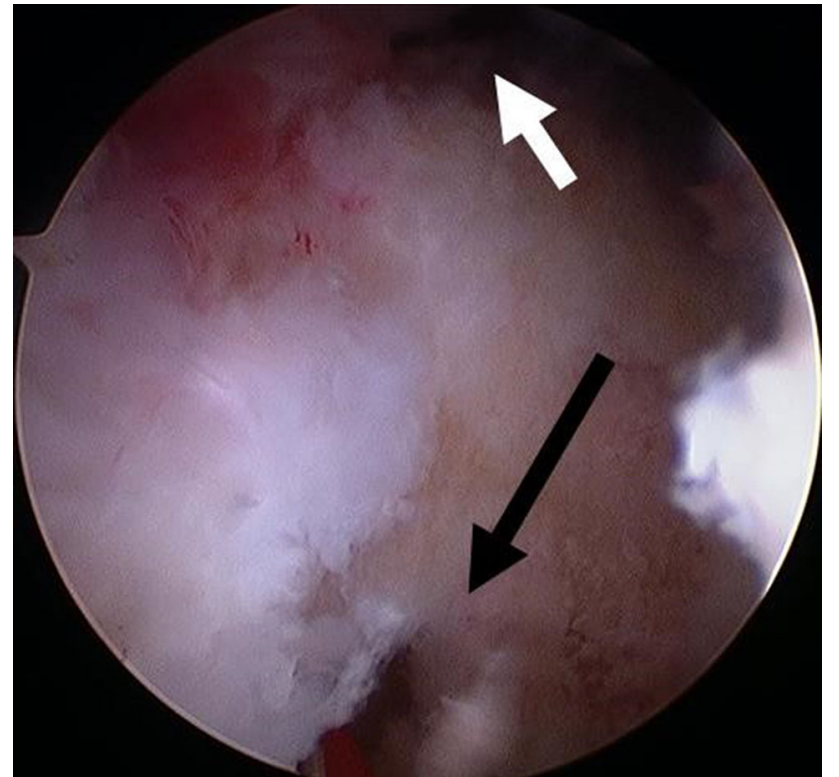

Fig. 6 View from the posteromedial portal of tibial socket (black arrow) at base of PCL facet (well below the joint line as denoted by the white arrow). (Reprinted from Operative Techniques in Sports Medicine, King AH, Prince MR, Reardon PJ, Levy BA, Stuart MJ, All-Inside Posterior Cruciate Ligament Reconstruction, Article in Press, Copyright (2015), with permission from Elsevier. http://www.sciencedirect.com/science/journal/10601872). visualization of the guide pin as it enters the insertion site and ensures no neurovascular compromise [3]. I exchange the $2.4 \mathrm{~mm}$ guide pin for a $3.5 \mathrm{~mm}$ retro cutting device and drill it into the tibial guide (Fig. 4). I then release the guide (Fig. 5A) and use it as a neurovascular shield (Fig. 5B). I deploy the retro cutting device, ream the socket, (Fig. 6), and insert a suture for graft passage purposes (Fig. 7).

At this point, the tibial socket is completed. Intraoperative imaging shows the final ACL and PCL reconstructions (Fig. 8). Anteroposterior (Fig. 9A) and lateral (Fig. 9B) fluoroscopic images obtained postoperatively demonstrate final ACL and PCL fixations.

Access to the distal attachment of the PCL on the tibia requires excellent visualization not only to ensure proper 


\section{Pearls}

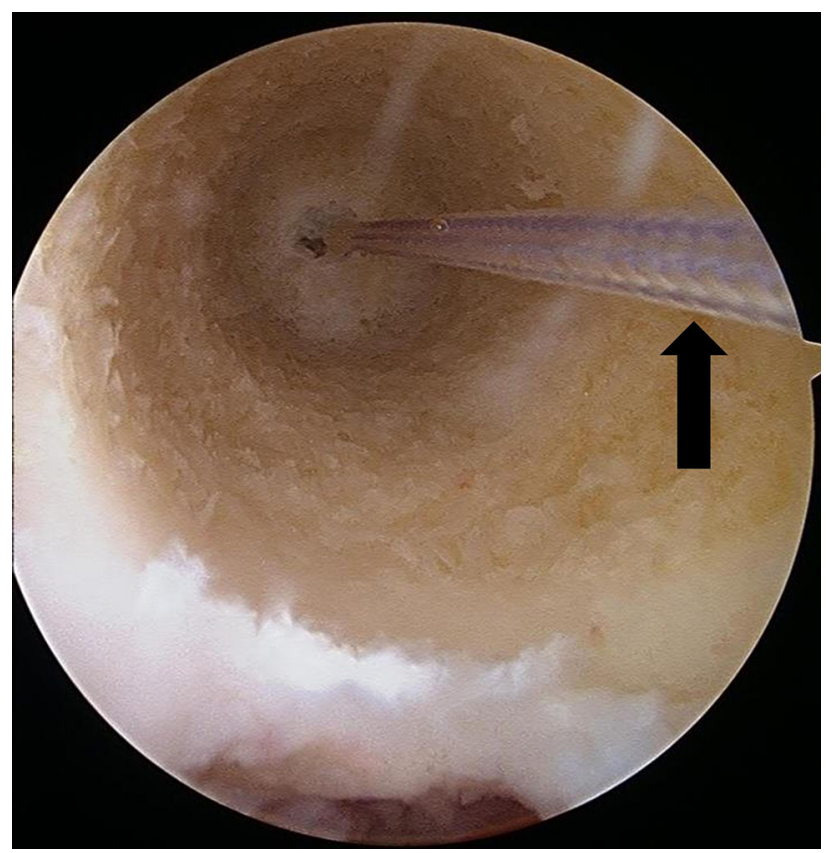

Fig. 7 View from the posteromedial portal of the tibial socket with suture (black arrow) for graft passage. (Reprinted from Operative Techniques in Sports Medicine, King AH, Prince MR, Reardon PJ, Levy BA, Stuart MJ, All-Inside Posterior Cruciate Ligament Reconstruction, Article in Press, Copyright (2015), with permission from Elsevier. http://www.sciencedirect.com/science/journal/10601872). 
Pearls

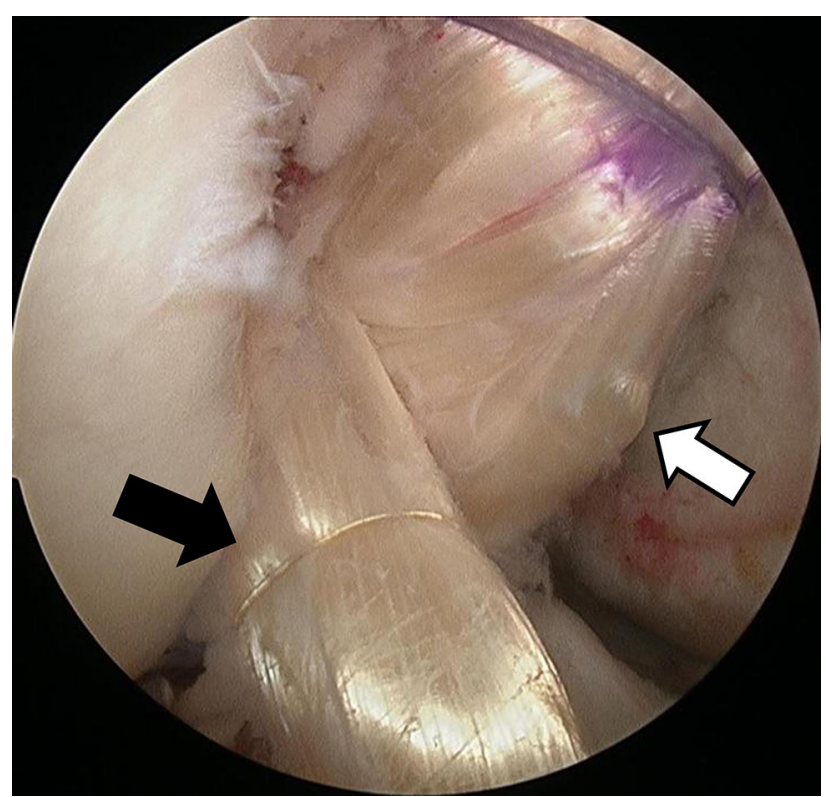

Fig. 8 View from anterolateral portal of $A C L$ (black arrow) and $P C L$ (white arrow) reconstructions. (Reprinted from Operative Techniques in Sports Medicine, King AH, Prince MR, Reardon PJ, Levy BA, Stuart MJ, All-Inside Posterior Cruciate Ligament Reconstruction, Article in Press, Copyright (2015), with permission from Elsevier. http://www.sciencedirect.com/science/journal/10601872). 


\section{Pearls}

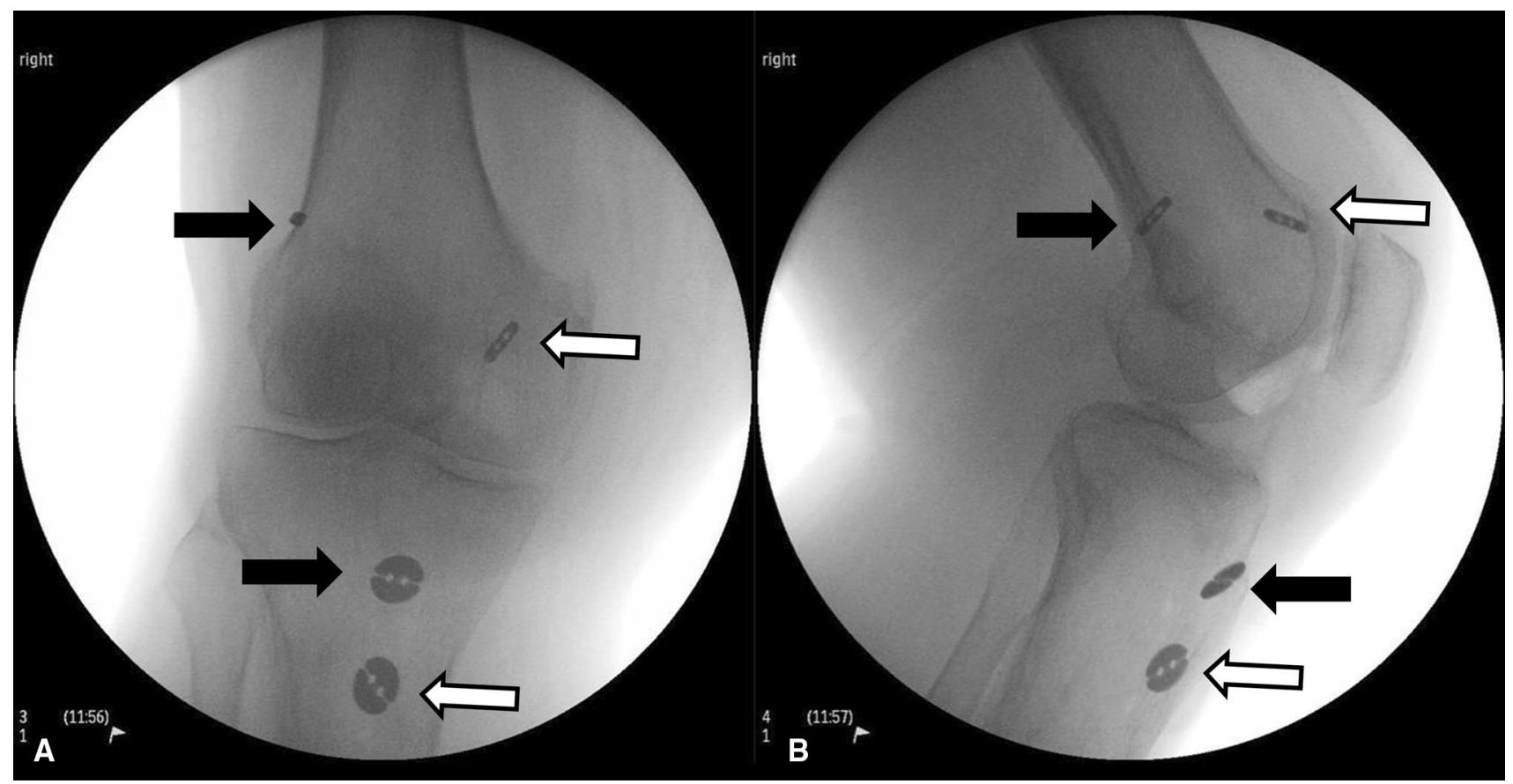

Fig. 9A-B (A) Fluoroscopic anteroposterior (AP) view demonstrating final ACL (black arrows) and PCL fixation (white arrows). (B) Fluoroscopic lateral view demonstrating final ACL (black arrows) and PCL fixation (white arrows). (Reprinted from Operative Techniques in Sports Medicine, King AH, Prince MR, Reardon PJ, Levy BA, Stuart MJ, All-Inside Posterior Cruciate Ligament Reconstruction, Article in Press, Copyright (2015), with permission from Elsevier. http://www.sciencedirect.com/science/journal/10601872).

positioning of the socket in its anatomic location, but also to prevent neurovascular injury.

\section{References}

1. Anderson CJ, Ziegler CG, Wijdicks CA, Engebretsen L, LaPrade RF. Arthroscopically pertinent anatomy of the anterolateral and posteromedial bundles of the posterior cruciate liga- ment. $J$ Bone Joint Surg Am. 2012;94:1936-1945.

2. King AH, Prince MR, Reardon PJ, Levy BA, Stuart MJ. All-inside posterior cruciate ligament reconstruction. [Published online ahead of print August 31, 2015]. Oper Tech Sports Med. DOI:10.1053/j.otsm.2015.06.012.

3. Levy BA, Boyd JL, Stuart MJ. Surgical treatment of acute and chronic anterior and posterior cruciate ligament and lateral side injuries of the knee. Sports Med Arthrosc. 2011;19:110-119.

4. Levy BA, Fanelli GC, Miller MD, Stuart MJ. Advances in posterior cruciate ligament reconstruction. Instr Course Lect. 2015;64:543-554.

5. Miller MD, Kline AJ, Gonzales J, Beach WR. Vascular risk associated with a posterior approach for posterior cruciate ligament reconstruction using the tibial inlay technique. $J$ Knee Surg. 2002;15:137-140. 